\title{
Administración y gasto de las cajas de comunidad en la Audiencia de Guatemala: el corregimiento de Quetzaltenango, 1790-1820
}

\section{Administration and Expenditure of Community Treasury in the Audiencia of Guatemala: Quetzaltenango, 1790-1820}

\author{
Selvin ChiQuín \\ Universidad de San Carlos, Guatemala
}

\begin{abstract}
Resumen: El presente artículo estudia el desarrollo institucional y económico de las cajas de comunidad en los pueblos de indios del corregimiento de Quetzaltenango, en la Audiencia de Guatemala, a finales del período colonial. El trabajo inicia con un análisis de las principales reformas que afectaron a los bienes comunales desde mediados del siglo xvIII hasta la crisis monárquica. Enseguida, se estudian las fuentes de ingreso y los gastos de los pueblos de indios. La relevancia de este trabajo consiste en analizar las demandas económicas impuestas por individuos ajenos a la jurisdicción y por las urgencias de la monarquía. Finalmente, se brinda una mirada general de las cuentas para las tres décadas. Con ello, se resalta la importancia de estos fondos dentro de los pueblos de indios, la capitalización de la economía española y el sostenimiento de la monarquía del que participó la población india a inicios del siglo XIX.
\end{abstract}

Palabras clave: cajas de comunidad; administración colonial; reformas borbónicas; pueblos de indios; Quetzaltenango; Audiencia de Guatemala.

Aвstract: This article deals with the institutional and economic development of the cajas de comunidad in the pueblos de indios (Indian towns) in Quetzaltenango, in the Audiencia of Guatemala, at the end of colonial era. It begins with an analysis of the main reforms that affected the community treasuries between the mid eighteenth century and the crisis of the monarchy. The sources of income and the outlays of the Indian towns are later discussed. The relevance of the study is its analysis of economic demands imposed by individuals from outside the Quet- 
zaltenango jurisdiction, and the urgent needs of the monarchy, and, finally, the general view that it provides of the community funds in Quetzaltenango during three decades. Thus, the article underlines the importance of these funds in colonial Indian towns, the capitalization of the Spanish economy and the support provided to the monarchy by the Indian population in the early nineteenth century.

KeYWORDS: community treasury; colonial administration; Bourbon reforms; Indian towns; Quetzaltenango; Audiencia of Guatemala.

ReCEPCIón: 11 de febrero de 2020.

ACEPTACIÓN: 26 de marzo de 2020.

DoI: https://doi.org/10.19130/iifl.ecm.57.2021.18658

\section{Introducción}

Desde el siglo xvi, con la reducción de las poblaciones indígenas en pueblos, varias instituciones acompañaron el proceso de formación de las Repúblicas de Indios. Entre ellas pueden encontrarse a las cajas de comunidad, que tuvieron gran importancia desde su instauración a mediados de ese siglo, lo que quedó en evidencia por el interés que mostraron ministros eclesiásticos y reales para poder administrar dichos fondos.

Desde hace varias décadas han existido estudios importantes que han considerado a las cajas de comunidad dentro de sus análisis; éstos han sido de carácter local y regional y han abordado el tema de forma breve, o bien gracias a análisis más recientes que han tomado el tópico como su objeto de estudio; se puede decir que existe un surco trazado que no puede pasarse por alto. ${ }^{1}$ Hasta ahora, sin embargo, parecen echarse de menos trabajos que se enfoquen en un nivel provincial y expongan las dinámicas de un conjunto de pueblos administrados bajo un ministro español — corregidor, alcalde mayor o intendente, por ejemplo.

Quetzaltenango, como corregimiento a finales del período colonial, permite un acercamiento de este tipo. En primer lugar, debido a que cuenta con suficientes fuentes para reconstruir, desde la década de 1790 hasta los últimos años de vida colonial, el desarrollo económico de las cajas de comunidad de la población mayoritariamente k'iche' y mam. ${ }^{2}$ Las cuentas presentadas por este

\footnotetext{
${ }^{1}$ Los trabajos que han tenido mayor relevancia al respecto, para el caso novohispano, son los de Tanck de Estrada $(1994 ; 1999)$ y Menegus $(2001)$, entre los más recientes. Para Guatemala, puede verse Cox-Collins (1980), Solórzano (1985), Fry (1988), McCreery (1992; 1994), León (2002) y Sagastume (2015).

${ }^{2}$ Otras provincias, en lo que ahora es Guatemala, también cuentan con un registro bastante completo, especialmente Totonicapán, Chiquimula de la Sierra y Verapaz. De forma más parcial pueden encontrarse documentos para Sololá, Sacatepéquez, Chimaltenango, Escuintla y Suchitepéquez. Para el caso de las intendencias de la Audiencia, a partir de finales de la década de 1780, es preciso hacer una búsqueda de fuentes entre los fondos albergados en el Archivo General de Centro América (AGCA) y otros repositorios documentales de la región centroamericana.
} 
corregimiento se asemejan a las de otras jurisdicciones de la Audiencia por lo que, a pesar de que se trata de un estudio particular, es posible que pueda aportar al conocimiento de la temática para el Reino de Guatemala y otras regiones de Latinoamérica. No puede obviarse la complicada situación socioeconómica y política en los albores de la ruptura con la metrópoli que vivió la jurisdicción, en consonancia con la situación general de la época. Por ello, es importante preguntarse si estos aspectos influyeron en el comportamiento de los bienes comunales en los pueblos de indios.

El presente artículo se trabajó a partir de las cuentas de oficiales reales y corregidores. Adicionalmente, se revisó legislación y peticiones para enriquecer la información. En este sentido, el trabajo se divide en tres partes. En la primera se presenta un repaso de los aspectos más importantes con respecto a las cajas de comunidad y las disposiciones que cambiaron la administración de estos fondos desde mediados del siglo xvil. También se hace una revisión de los ingresos que percibían las cajas y su relación con la población tributaria. En la segunda parte se trata el tema del gasto y cómo se repartían los fondos: escuelas, epidemias, obras públicas, crédito y, finalmente, en el auxilio de la monarquía. En el último apartado se presentan algunas explicaciones generales sobre el desarrollo de las cajas en las tres décadas estudiadas mediante la pormenorización de sus estados anuales.

\section{Administración, reformas y “comunidad"}

Desde mediados del siglo xvi, en los recién formados pueblos de indios, se establecieron una serie de instituciones que tuvieron su origen en la tradición jurídica castellana, incluida la "comunidad". En términos económicos, ésta tuvo importancia en tanto significó el reconocimiento de los bienes pertenecientes al “común” de los indios (Lira, 1984: 79-81). Eran, "en la práctica, [...] una significación tangible, al distinguirse, como bienes de comunidad, a los bienes comunes o públicos de una colectividad" (García, 2005: 102).

En este sentido, ligada a la creación de cabildos, la caja de comunidad estuvo presente desde que se ordenó en 1554 su creación (García, 2005: 102; Fry, 1988: 113). Como indican varios autores, el término "comunidad" significó, durante los años de dominación hispánica, el patrimonio colectivo que se tradujo, en el lenguaje administrativo de los documentos, como "bienes de comunidad" y "caja de comunidad" (Tanck, 1999: 34; García, 2005: 102). Como puede verse en la Recopilación de Leyes de Indias y en la normativa acumulada entre los siglos xVI y xix, el asunto ocupó a los gestores de la administración indiana para organizar dichos bienes (Lira, 1984: 81-82).

Este fondo era importante en tanto suplía necesidades como la compra de maíz, la adquisición de tierras, el auxilio en caso de epidemias, incendios, entierros, y también era significativo — pese a las restricciones- en el pago de 
tributos y de los curas cuando era difícil cubrir tales rubros. Los bienes de los pueblos de indios, depositados en la caja de comunidad de cada pueblo, estuvieron protegidos por una concepción general de amortización de la propiedad corporativa, al menos hasta mediados del siglo xvIII (Sagastume, 2015: 49-50).

La caja de comunidad se alimentaba de ingresos provenientes de la venta de los productos de la tierra cultivados en la llamada "milpa de comunidad", del arrendamiento de tierras comunales y, además, de una cantidad considerable de derramas que a menudo se imponían para sufragar las erogaciones comunes, al menos hasta mediados del siglo xvIII, que tenían que ver en buena medida con fiestas religiosas y otras necesidades internas de la comunidad (cfr. Sagastume, 2015: 51). Además, la cuota de comunidad se impuso como carga individual a cada tributario. Desde el inicio, dada la importancia de los curas doctrineros a nivel local, fueron éstos los que tuvieron mayor injerencia en el manejo de los fondos, junto con otros ministros como corregidores y alcaldes mayores que, entre los siglos xVI y xVII, gracias a una serie de disposiciones de la Corona, ganaron terreno frente a los religiosos (Tanck, 1999: 56; Cox-Collins, 1980: 175-177).

La naturaleza de la caja de comunidad varió con el tiempo. Por ejemplo, para el caso de Jacaltenango, en la alcaldía mayor de Totonicapán, se sabe que desde el siglo xVII hasta mediados del siglo xvII, los mayores beneficiarios de este fondo fueron los ministros reales y eclesiásticos de la región y que, como resultado de varias epidemias y los constantes déficits de los fondos, para 1753 la caja estaba completamente agotada. ${ }^{3}$ Sin embargo, es notable que, para 1780, la institución mutó gracias a una serie de innovaciones (Cox-Collins, 1980: 179-203).

Lo anterior no sorprende si se considera que, durante el siglo xvIII, gracias al relevo de dinastía gobernante de los reinos indianos, una gran cantidad de instituciones y prácticas fueron sometidas a una serie de cambios que la historiografía denomina como "Reformas borbónicas". Los pueblos de indios y su gobierno no fueron ajenos a éstas y los cambios fueron perceptibles desde las primeras décadas de la centuria. A diferencia de lo acontecido en los siglos anteriores, la política borbónica buscaba cambiar el relativo nivel de autonomía que los pueblos habían gozado hasta entonces. Como resultado, estos fondos a menudo estuvieron a disposición de las necesidades de la Corona (McCreery, 1994: 18). Ciertamente, las reformas se agudizaron después de la segunda mitad del siglo xVIII (Tanck, 1999: 17-23).

A finales de siglo se implementó una de las innovaciones más importantes en el proyecto borbónico, a saber, el régimen de intendencias, que modificó buena parte de la estructura administrativa a lo largo de todo el territorio indiano (cfr. Pietschmann, 1996: 301). Para el caso de la Audiencia de Guatemala, la aplicación de la Real Ordenanza de Intendentes fue bastante particular, pues

\footnotetext{
${ }^{3}$ El aprovechamiento y desvío de estos fondos para los intereses de los ministros locales fue algo bastante común, incluso a finales de la época colonial, pese a las restricciones impuestas con carácter más severo. Véase, para el caso de los Cuchumatanes a Lovell, 2015: 147-148.
} 
dio vida a cuatro intendencias con sus modificaciones jurisdiccionales (Ciudad Real, San Salvador, Comayagua y León), pero mantuvo algunas alcaldías mayores y corregimientos bajo el modelo anterior, así como la gobernación de Costa Rica y otros territorios con control eminentemente militar (Dym, 2006: 51, 306; López Mejía, 2017: 143).

Pese a que la implementación del régimen de intendencias fue progresiva y poco dada a la homogeneidad en la Audiencia de Guatemala, los artículos de la ordenanza fueron vistos y aplicados en donde así lo ameritaba. También es preciso anotar que, aunque las alcaldías mayores y corregimientos seguían en funcionamiento y no se habían transformado en subdelegaciones, varias de las disposiciones ahí establecidas servían para el gobierno de estas jurisdicciones. ${ }^{4}$ Lo mismo aplicó para lo referente a los fondos de comunidad. El artículo 28 establecía que, para uniformar el gobierno de este particular, se mandaba que la Junta Superior de Hacienda tuviera la inspección de dichos fondos de forma privativa. Esto con la jurisdicción establecida en el artículo 6. El siguiente apartado constituía que la misma Junta Superior instituyera una regla general para la administración del ramo y se comunicara por medio del contador general de propios y arbitrios. Posteriormente se enfatizaba que los intendentes tuvieran razón, de la mano de las justicias de ciudades, villas y pueblos, de los bienes comunes, lo que incluía, por supuesto, a las cajas de comunidad, para la formación de reglamentos particulares a cada pueblo, entre otros aspectos (Real ordenanza, 1786: $9-10$ y $35-36) .^{5}$

Pronto fueron necesarios algunos ajustes frente a la realidad de las jurisdicciones. Así lo muestra la Real Orden expedida en 1788, en la que se derogaban los artículos 6 y 28 de la Real Ordenanza de Intendentes, pues se admitía que era mejor si se proponía la inversión de los capitales de los propios y arbitrios de villas y ciudades, así como los bienes de comunidad de los pueblos de indios, por parte de las justicias y se aprobaba en la Real Audiencia, minando las competencias de la Junta Superior de Real Hacienda para el efecto. ${ }^{6}$ Adicional a ello, la Contaduría de propios, arbitrios y bienes de comunidad tomó un papel importante en el manejo de estos caudales mediante la rendición de pareceres ante la Audiencia sobre los gastos habidos en las jurisdicciones. ${ }^{7}$

En Quetzaltenango, el efecto de las reformas puede verse en la reorganización del ramo y en la cantidad de documentos producidos a raíz de ello. El ingreso

\footnotetext{
${ }^{4}$ Las jurisdicciones circundantes a la ciudad de Guatemala, que no se modificaron, estaban a cargo, en varios aspectos, de la Superintendencia General en manos del presidente de la Audiencia. El ayuntamiento de la ciudad desempeñó un papel fundamental en el mantenimiento de estas jurisdicciones. Véanse Zilbermann, 1995: 35 y López Mejía, 2017: 142-143.

${ }^{5}$ Sobre el particular no se han podido identificar, hasta el momento, reglamentos propios para cada pueblo en la jurisdicción de la Audiencia de Guatemala. Sin embargo, para el caso novohispano se encuentra bien documentado en Tanck, 1999: 22, 27.

${ }^{6}$ AGCA, A1, leg. 12, exp. 285.

${ }^{7}$ AGCA, A1, leg. 272, exp. 5865.
} 
que siempre se percibía de manera anual dependía de la contribución obligatoria $\mathrm{y}$, en el caso del pueblo cabecera, del arrendamiento de 15 tiendas en el portal de comercio de Quetzaltenango y de algunas pajas de agua.

Desde el siglo xvi hasta 1805 puede encontrarse, en el estado presentado por los corregidores, además del tributo y la contribución de comunidad, un cobro conocido como "quebrado acrecido", que consistía en los sobrantes del pago de tributos. Para el caso chiapaneco, Obara-Saeki y Viqueira (2017: 277-280) evidencian esta forma de pagar la cuota de comunidad como la diferencia resultante del pago del tributo calculado con los precios de las especies con las que se solía pagar en cada tercio, redondeados al alza, y el cálculo de los precios oficiales. En Quetzaltenango, mientras que el producto de siembras de comunidad aportaba, en promedio, un poco más de 3,000 pesos anuales a las cajas en todo el corregimiento, el quebrado acrecido sumaba alrededor de 300 pesos. ${ }^{8}$ Este cobro había sido suprimido en 1801 (León, 2002: 14); sin embargo, es notable que para la mayoría de las jurisdicciones aún se presentara el producto de este ramo en los estados elaborados por los ministros cuatro años después de la supresión. ${ }^{9}$

Los datos sobre las contribuciones de cada indio, en concepto del trabajo de la milpa comunal, son variados, pues la contribución solía ser de 11/2 reales desde finales del siglo xvı. La cifra aumentó considerablemente a finales del período colonial. Según una providencia de 1806 , se impuso en cuatro reales la contribución de cada indio a la caja comunal, lo cual se puso en vigencia de inmediato, tal y como lo evidencian las cuentas a partir de 1807, al incluir en el cargo que el renglón de la contribución de cada uno se hacía "con arreglo a la superior providencia del tribunal de la Real Audiencia". ${ }^{10}$ Esto no modificó, más allá de lo legal, el importe para los caudales en Quetzaltenango, pues desde el siglo xvIII se cobraba esa cantidad.

La cantidad de tributarios, en la última década del siglo xvili, se mantuvo uniforme, al menos en las cuentas de los oficiales reales. El número de contribuyentes en Quetzaltenango era igual a 7,333 repartidos en 26 pueblos que contribuían en 25 partidas. ${ }^{11}$ Según esto, la contribución obligatoria debía ser de 3,666 pesos y 4 reales, por lo que la razón de la cifra esperada anualmente no tomaba en cuenta el producto que importaba la renta de las tiendas y pajas de agua en el pueblo cabecera, así como tampoco implicaba la contribución que algunos ladinos aportaban en los pueblos de Tejutla y Tacaná para los últimos años de la

\footnotetext{
${ }^{8}$ Véanse los cuadros presentados en el último apartado. La Intendencia de Ciudad Real era la que más consignaba en ingresos de quebrado acrecido (poco más de 6,000 pesos anuales). Para todos los partidos de la Audiencia, a finales del siglo xvIII, se consignaban casi 14,000 pesos en este rubro. AGCA, A1, leg. 6099, exp. 55567.

9 AGCA, A1, leg. 2166, exps. 15609 y 15613; AGCA, A1, leg. 2167, exp. 15620, AGCA, A3, leg. 2522, exp. 36741 .

${ }^{10}$ AGCA, A3, leg. 5771, exp. 56750.

${ }^{11}$ Pese a ser dos pueblos, San Pablo y Malacatán, aparecían en la misma partida.
} 
década de 1810, dada la inclusión "voluntaria" de los mismos en las cuentas. ${ }^{12}$ Espíritu Santo Quetzaltenango era, notoriamente, el pueblo que más contribuía, con 565 pesos anuales, seguido por Santa Catarina Zunil (395 pesos). ${ }^{13}$ A estos datos faltaría agregar lo correspondiente al fundo legal y tierras adquiridas en calidad de comunales para sufragar los gastos de comunidad que, como se ha visto en otras jurisdicciones, es información que se encuentra consignada en los reglamentos de cada pueblo (Menegus, 2001: 89-99).

\section{Entre la necesidad, los préstamos y el bien de la monarquía}

Escuelas de primeras letras

Desde finales del siglo xvII hasta los últimos años de la Colonia, el gasto de maestros, en donde así se había instituido, fue la erogación más común y que se liquidaba de manera ininterrumpida por los bienes de comunidad, a menos de que eventualidades con carácter urgente no lo permitieran. En este sentido, las escuelas que debieron establecerse en los pueblos de indios dependieron directamente de estos fondos y, por ende, como se explica para el caso yucateco, la reorganización de las cajas y la fundación de escuelas fueron procesos análogos (Tanck, 1994: 401). En el Reino de Guatemala estuvo relacionado con la política educativa borbónica que, a partir de la segunda mitad de la centuria y hasta el inicio de la crisis de la monarquía, promovió el aumento de escuelas extendiéndolas a los indígenas (Herrera, 2007: 25-29).

Buena parte de la extensión de la educación de primeras letras a la población india se debió a su capacidad para sufragar los gastos, según observaron los oficiales de la Corona. Aunque los bienes comunales cubrían en su mayoría los costos en la instrucción hasta bien entrado el siglo xviII, fue a finales de la década de 1770 que se especificó que las cajas de comunidad estaban obligadas a pagar los salarios de los maestros (Herrera, 2007: 32). ${ }^{14}$

Como se mandaba en las distintas disposiciones legislativas dadas a finales del siglo xviII, las cuentas anuales debían acompañarse de los comprobantes de los gastos de cada pueblo. Esto también incluía los recibos de pagos a maestros que, pese a su brevedad, clarifican algunos aspectos relativos a lo que se ense-

\footnotetext{
12 AGCA, A1, leg. 2168, exp. 15649, f. 1. Para la población total y tributaria en el siglo xvIII e inicios del siglo XIX véase Lovell et al., 2013: 280-283.

13 AGCA, A1, leg. 2168, exp. 15624, f. 1.

14 Dado que no es intención del presente artículo ahondar en aspectos más específicos de la enseñanza, los métodos y la formación de instrumentos para las escuelas en los pueblos de indios, puede consultarse para ello el voluminoso expediente ubicado en AGCA, A1, leg. 260, exp. 5736. Para una ampliación sobre la enseñanza en los pueblos de indios novohispanos véase Tanck, 1999: 337447. Este tema es uno de los grandes pendientes de la historiografía a finales del Antiguo Régimen para el caso guatemalteco. Pese a ello, se cuenta con el excelente trabajo de Herrera (2007) para la alcaldía mayor de Sonsonate y la Intendencia de San Salvador.
} 
ñaba en las escuelas de primeras letras. Por lo general, el cura de la parroquia que administraba el pueblo era quien certificaba que el maestro había servido, durante el tiempo establecido, como maestro de escuela de niños indios, "enseñándoles a leer, escribir y el idioma castellano, y en él la doctrina cristiana”. Acto seguido, el maestro hacía constar que había recibido el dinero de manos del corregidor. ${ }^{15}$

Fue posterior a la remisión de un método de enseñanza y de un auto acordado de la Real Audiencia, en 1799, que se fomentó la instalación de varias escuelas, completamente sufragadas por los bienes de comunidad, en el corregimiento de Quetzaltenango. De ahí que entre 1800 y 1801 se hayan invertido 368 pesos y 5 reales para la compra de cartillas y catones, entre otros gastos relacionados. Adicionalmente, fue a partir de este período que se comenzó a sufragar el salario de maestros, a saber, de unos 1,400 pesos en toda la jurisdicción. ${ }^{16}$ Nuevamente, en 1803 , se registró otra compra de cartillas y catones por 175 pesos. ${ }^{17}$

A partir de la segunda mitad de la década de 1810 , no se consignaron más gastos que los sueldos de maestros, pagados sin interrupción y cuyo rubro rara vez sobrepasó los 1600 pesos anuales para las 16 escuelas que existían en el corregimiento. La oscilación —que podía ir de 1,100 a 1,600 pesos, aproximadamente-, se debía a que, en ocasiones, sólo se pagaba cierta cantidad de meses o, en otros casos, se saldaban deudas anteriores. Por supuesto, los salarios no eran uniformes, pues dependía del número de tributarios de cada pueblo y, por tanto, de lo que podía contribuir la caja para sufragar esa erogación.

También resalta que los pueblos de Santa María de Jesús, San Mateo, San Miguel Sigüilá, San Cristóbal Cabricán, San Cristóbal Cuch, Santiago Coatepeque, San Pablo, Malacatán y San Bartolomé Sipacapa no contaban con escuela propia, pues no sobrepasaban los cien tributarios. Por su parte, aunque San Antonio Sacatepéquez cumplía con este requisito, únicamente tenía 11 tributarios más de lo que se solicitaba para instalar una nueva escuela y su caja apenas superaba los 50 pesos de ingresos anuales, lo cual no hubiera alcanzado para pagar los 60 pesos de sueldo que percibían los maestros con menor paga. No se pudo determinar si los niños de estos pueblos asistían a otras escuelas cercanas; sin embargo, según las cuentas, se sabe que tales fondos se consideraban sobrantes.

\section{Epidemias}

Otro de los rubros que captaron buena parte de los fondos comunales fueron las epidemias, tanto para su prevención por medio de la inoculación, como en la asistencia a pueblos que las habían padecido. Por ejemplo, dado que los esfuerzos por contener la viruela datan desde 1780 , las cajas de comunidad tuvieron

\footnotetext{
15 Véase, por ejemplo, AGCA, A1, leg. 6098, exp. 55548.

16 AGCA, A1, leg. 2166, exp. 15607, f. 2.

17 AGCA, A1, leg. 2166, exp. 15613, f. 2.
} 
un papel central en sufragar dichos gastos. En ello también fueron importantes los protomédicos en las campañas contra las epidemias a lo largo de toda la jurisdicción, especialmente con la introducción de la vacuna a inicios del siglo xIX (Few, 2015: 11-12).

Las epidemias modificaron la vida al interior de los pueblos de indios. Más allá de las consecuencias demográficas, aspectos como la comida y las medicinas, relacionados con la subsistencia, así como las reducciones de tributo, fueron fundamentales para la sobrevivencia de la población. Estos elementos estuvieron, a menudo, vinculados con las cajas de comunidad y la mediación de ministros civiles y eclesiásticos frente a las autoridades en la capital (Few, 2015: 33-34).

Las cuentas de las cajas de Quetzaltenango muestran cómo se vieron afectadas las erogaciones por las epidemias entre 1790 y la década de 1810. Esto, sin duda, respondió a la gran cantidad de amenazas y su prevención a finales del período colonial. Entre 1780 y 1820 puede rastrearse la influencia, en la afección a los pueblos del altiplano guatemalteco, de epidemias de viruela, tabardillo y sarampión, principalmente. ${ }^{18}$ En el rubro que cubría estas urgencias se incluía, también, el sueldo percibido por el protomédico encargado de la inoculación de los pueblos, al cual contribuían todas las jurisdicciones de la Audiencia en caso de que se emprendieran campañas antiepidémicas.

En 1796, por ejemplo, el pueblo de Tajumulco fue afectado por una epidemia de viruela. Para socorrerlo se utilizaron 359 pesos y $2^{\frac{1}{2}}$ reales de su cajuela de comunidad. Sin embargo, tal cantidad no fue suficiente, pues debía cuidarse que no se propagara más, por lo que el tribunal de la Real Audiencia resolvió que se sacara, de las demás cajas del corregimiento, la cantidad necesaria en calidad de reintegro para tal efecto. Por tanto, fue egreso de ese año la cantidad de 732 pesos y 5 reales de las cajas de los demás pueblos de Quetzaltenango. ${ }^{19}$

Cuatro años después de lo sucedido en Tajumulco, en 1800, una epidemia de viruela afectó a la mayoría de pueblos del corregimiento de Quetzaltenango, por lo que se gastó, en total, 3,886 pesos y $3 / 4$ reales para mitigarla. ${ }^{20}$ Tres años más tarde todavía se intentaba aislar la enfermedad, para lo que se contribuyó con 115 pesos y 4 reales de todas las cajas. ${ }^{21}$ Pese a que después de 1805 las cuentas empezaron a mostrar bajas considerables, debido a las presiones de la Corona sobre estos fondos, aún existían salientes dirigidos a la vacunación, tal y como lo muestra una data de 1809 , en que se destinaron 325 pesos y $3 \frac{1 / 4}{4}$ reales para pagar las vacunaciones, y otra de 1818 , con 164 pesos y 2 reales para lo mismo. ${ }^{22}$

La cura de epidemias requería más esfuerzos, así como también necesitaba una cantidad considerable de insumos para atender a los enfermos. En San Mi-

\footnotetext{
$18 \mathrm{Al}$ respecto, puede verse con más detenimiento lo que se muestra en Lovell, 2015: 208-211.

${ }^{19}$ AGCA, A1, leg. 2166, exp. 15598, f. 2.

${ }^{20}$ AGCA, A1, leg. 2166, exp. 15607, f. 2.

21 AGCA, A1, leg. 2166, exp. 15613, f. 2.

22 AGCA, A1, leg. 2168, exp. 15656, f. 2.
} 
guel Ixtahuacán hubo una epidemia de fiebre en 1813, para lo cual se necesitaron varios desembolsos en dietas de los encargados de curar a la población, medicamentos, alimentos y otros productos dirigidos a la esterilización y asepsia. Entre las actividades de los comisionados se encontraba la preparación de hospitales improvisados, visita de pacientes y elaboración de bebidas especiales. ${ }^{23}$

Un primer pago se hizo para cubrir el costo de medicamentos, que sumó 8 pesos y $3 \frac{1}{2}$ reales, además de 196 pesos de dietas a Ignacio Ruiz de Ceballos, encargado de la curación. En el segundo caso fueron 247 pesos y 3 reales de medicamentos, 448 pesos de dieta a don Cirilo Flores —el hijo de Joseph Felipe Flores-y, finalmente, 399 pesos y reales por alimentos y otros productos destinados a la curación y recuperación de los afectados. ${ }^{24}$

Los esfuerzos de los encargados de emprender las campañas de inoculación, así como la ayuda prestada por medio de las erogaciones de las cajas de comunidad, pudieron influir en que la tasa demográfica no cayera dramáticamente, aunque no se cuenta con la evidencia suficiente para aseverarlo. Además, aunque estas medidas pudieran evitar, en parte, la reducción de la población india, siempre resultaba inevitable el deceso de individuos en los pueblos mayormente afectados. ${ }^{25}$

\section{Gastos permitidos}

Como se ha dicho anteriormente, para el gasto de los bienes de comunidad, además de los que se encontraban reglamentados, se necesitaba un proceso que incluía la petición por parte del común y el corregidor, el dictamen del oficial de la mesa de propios, arbitrios y bienes de comunidad, la opinión del fiscal y, finalmente, el auto de la Real Audiencia. Todas las erogaciones pretendidas eran sometidas a un proceso de negociación en el que interactuaban varios ministros a distintas escalas administrativas. ${ }^{26}$

${ }^{23}$ Para más información sobre estos aspectos, véanse Few, 2015 y Solórzano, 2014.

24 AGCA, A1, leg. 2168, exps. 15641, 15642, 15643 y 15644.

25 Sobre los efectos de las campañas de inoculación a inicios del siglo xix y la reducción de la mortandad entre la población indígena véase Lovell, 2015: 226-231. Para datos demográficos sobre Quetzaltenango entre finales del siglo xvII e inicios del siglo xIx, véase el trabajo de González, 2017: 63-67; en él se enfatiza que, pese a las fluctuaciones demográficas del siglo xvIII e inicios del siglo xix, la población indígena había logrado una "extraordinaria tenacidad y adaptabilidad". Sobre la población tributaria en los últimos años coloniales véase Lovell et al., 2013: 280-283.

${ }^{26}$ Sobre la petición y los enredos institucionales en los que se involucraron varios indios novohispanos y los agentes de la administración, puede consultarse el excelente trabajo de Brian P. Owensby (2008), especialmente el capítulo 3. A diferencia de lo observado por Owensby para los siglos xVI y xVI, llama la atención que, para el arco temporal aquí estudiado, varios de estos mecanismos se hicieron más rígidos, tal y como lo ejemplifican las peticiones elevadas a la Real Audiencia por parte de los indios para hacer uso de sus cajas de comunidad. Ello coincide con el control riguroso impuesto por las políticas reformistas borbónicas a la institución (Tanck, 1999: 56-57). 
Para ejemplificar este aspecto, a continuación se presentan dos casos en los que dos pueblos, a saber, Espíritu Santo Quetzaltenango, la cabecera del corregimiento y, por otra parte, Zunil, se vieron involucrados en dos peticiones y tuvieron respuestas diferentes a las esperadas. Esto se debió al contenido de ambas pretensiones, así como a la mediación de los ministros de la Corona. En el primer caso (1796), el corregidor solicitó gastar 84 pesos para reparar la casa real de la cabecera; ${ }^{27}$ en el segundo (1797), el común de Zunil pidió pagar únicamente 2 reales en lugar de los 4 que debían enterar al fondo común. ${ }^{28}$

El 24 de enero de 1796 el corregidor de Quetzaltenango, don Prudencio de Cozar, elevó una petición a la Real Audiencia, explicando que desde 1794 los indios de la cabecera del corregimiento habían iniciado la reparación de la casa real cubriéndola con tejado. Sin embargo, a lo interno, la obra seguía dañada e inhabitable. Cozar explicaba en su petición que, anteriormente, estas reparaciones se hacían del producto de las tiendas de mesón y las pajas de agua que estaban rentadas y que paraban antiguamente en manos de los jueces indios. No obstante, al reformarse el cobro de las cajas y, con ello, haberse puesto este ingreso en la caja de comunidad, los indios se habían quedado sin fondos para continuar la reparación. Con la solicitud de licencia para gastar de estos fondos, también incluyó el reconocimiento de gastos hechos por los carpinteros Rafael Estefanía y Tomás Madrid, así como por los albañiles Isidoro Chuchuh y Cipriano López. El avalúo de los peritos albañiles estableció que el gasto en la compostura requeriría de 32 pesos. Por su parte, los carpinteros valuaron la obra en 52 pesos. ${ }^{29}$

El corregidor expuso lo benéfico que había resultado el traspaso a la caja de comunidad de los ingresos en concepto de rentas que tenían los indios de Quetzaltenango anteriormente en sus manos, diciendo que, en tiempos pasados, siempre se consumía en "reparos de obras públicas como cárceles, convento, cañerías y casa real, que todas ellas son propias del común". ${ }^{30}$ Don Tomás de Moreda, el oficial encargado de los propios, arbitrios y bienes de comunidad dio su visto bueno para que se hiciera el gasto. ${ }^{31}$

El fiscal de la Audiencia fue más moderado al respecto, explicando que al ser Quetzaltenango un vecindario compuesto por españoles, ladinos e indios no era conveniente que únicamente los indios tuvieran este gasto, citando la Ley $10^{\mathrm{a}}$, Título $4^{\circ}$ del Libro $6^{\circ}$ de la Recopilación de $1680 .{ }^{32}$ La propuesta de este ministro fue que se impusiera una derrama entre los vecinos más pudientes de la ciudad para asistir al reparo de las casas y se reintegrara con ello a la caja de los indios de Quetzaltenango. Con ello, los ministros de la Audiencia aceptaron que se hiciera el gasto, no sin antes advertir que fuera "bajo las calidades que propone

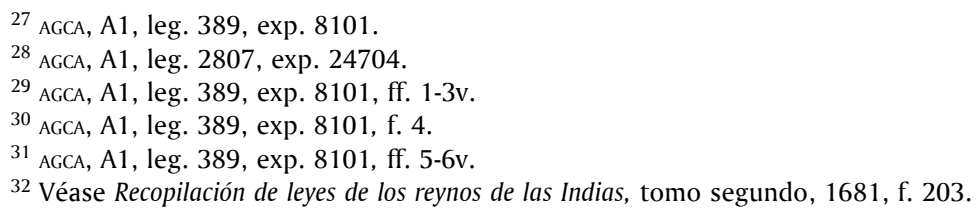


el fiscal", ${ }^{33}$ lo que provocó una reacción por parte del corregidor, indicando las condiciones y el uso que se le daba al edificio.

En efecto, Cozar informaba que "no solo las casas reales, sino es el cabildo, cárceles y ramo de aguas son propias del común de ellos y de tiempo inmemorial" ${ }^{34}$ Por ello, continuaba, era la justicia india la que corría con su conservación, compostura y erogación de los gastos necesarios que, como había explicado, se hacían de lo cobrado en concepto de rentas. Además, pedía que no se gravara a los ladinos del vecindario, aduciendo que los indios eran "tan delicados como idiotas" 35 y que, al enterarse que los ladinos habían tenido parte en el arreglo de la casa real, se habrían alzado buscando echar a la población ladina del pueblo, resultando disturbios "que si se despreciaran sería preciso hacernos cargo de las resultas". ${ }^{36}$ Gracias a esta explicación, el fiscal concordó con el corregidor y los ministros de la Audiencia permitieron que se hiciera de la forma propuesta.

El segundo pedimento tuvo lugar un año después, en 1797, en el pueblo de Santa Catarina Zunil. En el escrito de los alcaldes, justicias y principales de Zunil, se explicaba que en ese año habían experimentado varios quebrantos de salud y las cosechas habían sido muy malas. Por tanto, se pedía que únicamente contribuyera con dos reales cada familia y que, con posteridad, no se les obligara a sembrar milpa de comunidad, pues el corregidor los obligaba, decían, "en inteligencia que nuestro territorio es áspero y pedregoso, y por esta razón con grande fatiga logramos algún fruto". ${ }^{37}$ Apelando a su fidelidad como feudatarios del rey, explicaban que el pedimento no era de malicia y que era en atención a la justicia que les correspondía. Adicionalmente, solicitaban que el producto de las siembras de comunidad se les devolvieran a los principales del pueblo, en plata, para que fueran depositados en ellos y no en la caja que administraban los ministros de la Corona, agregando que, aunque la llave estuviera en poder del corregidor, era justo que se hiciera como llevaban dicho. ${ }^{38}$

El oficial real, que estaba comisionado para arreglar este ramo, fue de la opinión que se les admitieran los dos reales pues suponía que los motivos eran ciertos. Respecto al depósito del fondo de comunidad en manos de los principales, juzgó que se trataba de algo infundado, agregando que la existencia de las cajas en las casas reales era debida, precisamente, a su poca fidelidad. Por tanto, según él, se encontraba justificado el cambio de ubicación y el control de las cajas. ${ }^{39}$

33 AGCA, A1, leg. 389, exp. 8101, f. 8.

34 AGCA, A1, leg. 389, exp. 8101, f. 10.

35 AGCA, A1, leg. 389, exp. 8101, f. 10v.

36 AGCA, A1, leg. 389, exp. 8101, f. 11. A inicios del siglo xIX el ayuntamiento español de Quetzaltenango obtuvo el permiso para establecer una caja de ladinos que sería costeada, al igual que la de indios, por una contribución de 4 reales pedida a la población no india (Grandin, 2000: 70).

${ }^{37}$ AGCA, A1, leg. 2807, exp. 24704, f. 1v.

38 AGCA, A1, leg. 2807, exp. 24704, ff. 1v-2.

39 AGCA, A1, leg. 2807, exp. 24704, ff. 2-3v. 
Por su parte, el corregidor respondió a lo dicho por el oficial real mediante una exposición en la que desvirtuaba el pedimento de los indios. Dentro de los argumentos de Cozar se explicaba que, en tiempos anteriores, el producto de las cosechas había sido vendido y fácilmente habían cubierto la cuota de comunidad, por lo que no comprendía a qué se debía la rebaja solicitada, agregando que las enfermedades y las malas cosechas no habían tenido lugar. Agregó que, aunque era cierto que el fundo legal de Zunil era árido y montuoso, en la costa tenían terrenos con siembras de maíz. No dudó en afirmar que los indios de Zunil eran los "más comerciantes y viajeros de la provincia de consiguiente, ricos en su clase" ${ }^{40}$ Como muestra de ello, Cozar señaló que se viera la iglesia y la plata allí resguardada que, según su opinión, era gastada en fiestas y ebriedades. Ante esta exposición, el fiscal no dudó en darle razón a Cozar. La Audiencia, entonces, denegó la solicitud de los indios de Santa Catarina Zunil. ${ }^{41}$

Para finalizar este apartado, debe establecerse que el caso es importante para comprender cómo se dirimieron los asuntos administrativos, respecto a las cajas de comunidad $-\mathrm{y}$, en realidad, sobre varios asuntos relacionados con las repúblicas de indios-, a varios niveles y cómo la negociación y las estrategias de los indígenas se toparon, frecuentemente, con instancias que influían en la toma de decisiones en diversos niveles de la administración colonial. En último caso, de los ministros dependían las concesiones y la flexibilidad de las disposiciones legales.

\section{Fuente de crédito}

A inicios del siglo xIx, la economía del Reino de Guatemala se vio en aprietos, debido a la coincidencia de dos aspectos que marcaron el destino del istmo: la crisis fiscal de la monarquía y, por otro lado, la depresión del reino, causada por una plaga de langostas, las medidas fiscales de la Corona y los problemas acarreados por las tensiones en torno a la producción y comercialización del añil (Wortman, 2012: 233-238). La descapitalización acompañó estos años, por lo que la diversificación de fuentes de crédito fue inminente.

Las fuentes de financiamiento eran diversas y, buena parte de ellas, eran parte del patrimonio de comerciantes, ministros e instituciones eclesiásticas que, desde el siglo xVII, se convirtieron en espacios importantes de circulación económica y de formación de redes relacionadas con lazos familiares, profesionales, entre otros. Durante el siglo xvIII, el capital administrado por estas fuentes creció de manera importante y fueron fundamentales para una gran cantidad de operaciones económicas (Belaubre, 2012: 279-294).

\footnotetext{
40 AGCA, A1, leg. 2807, exp. 24704, f. 5v.

41 AGCA, A1, leg. 2807, exp. 24704, ff. 7v-9.
} 
Los fondos de comunidad también tuvieron un papel importante en el financiamiento de las empresas económicas, no obstante, los mecanismos diferenciados utilizados para la concesión de estos capitales. De ello hay que mencionar que la vocación crediticia de los bienes comunales de los pueblos de indios explica cómo estos fondos financiaron, desde finales del siglo xvIII, a particulares con la mediación de la administración española (Terán, 1999: 221-223). En el Reino de Guatemala, a partir de la década de 1760 , por lo menos, puede notarse un aumento considerable en transacciones y montos tomados de dichos fondos a cambio de una renta anual y un tiempo estipulado - dos años, por lo generalpara pagar el total del capital (León, 2002: 66-75).

La figura utilizada para la transacción crediticia se llamó "usura pupilar", la cual consistió en una renta anual del 5\% sobre el total del préstamo, que se daba por medio del establecimiento de una hipoteca o la presentación de fiadores, aunque en varios casos ambas seguridades fueron requisito para dar el préstamo. Este fue el mecanismo más utilizado por entonces, ya que desde la década de 1680 se usaba en Guatemala por las instituciones eclesiásticas más abonadas. ${ }^{42}$ En este sentido, como nota Oralia de León, los montos de los préstamos, mediante la usura pupilar, oscilaron entre los 500 y los 15,000 pesos, lo que es un indicador de qué tanto pudieron capitalizar las operaciones comerciales y agrícolas de la época (León, 2002: 69-70).

Fueron las intendencias las que movieron mayor cantidad de capital para financiar actividades económicas. Resaltan, en este sentido, las cajas de comunidad de San Salvador, Ciudad Real y León, que se mantuvieron constantes en las dos décadas anteriores a la Independencia como fuentes de crédito. Hacia 1805, por ejemplo, San Salvador tenía 70,163 pesos $4 \frac{1}{2}$ reales prestados, mientras que Ciudad Real sobrepasaba los 54,000 pesos. El caso de Quetzaltenango, que es el que reviste mayor interés en este trabajo, quedó ciertamente relegado en tal sentido (con apenas un préstamo de 1,000 pesos para 1805), pues otras jurisdicciones de la Audiencia como Chiquimula de la Sierra (16,500 pesos para entonces) y la misma capital $(15,500$ pesos prestados hacia 1809$)$ se mantuvieron con mayores caudales en su papel de acreedoras. ${ }^{43}$ Ello se relaciona, en gran medida, a los ingresos anuales que tenían los bienes de comunidad en las jurisdicciones del reino, como se verá en el último apartado.

Las cantidades dadas en usura pupilar disminuyeron en la segunda mitad de la década de 1800 , especialmente porque se aceptó que no siempre era rentable prestar, ya que los deudores se atrasaban con los réditos y el pago del total o, en otros casos, directamente omitían la cancelación de la deuda (León, 2002: 72-75).

\footnotetext{
${ }^{42}$ Es importante señalar que esta dinámica también fue común en el contexto mexicano en el que, a partir de finales del siglo xvII, el depósito irregular - figura crediticia casi idéntica a la obligación a renta pupilar - se utilizó con más frecuencia. Véase Von Wobeser (2010: 66-76).

43 AGCA, leg. 380, exp. 7861; leg. 382, exp. 7948; 1805. / AGCA, A1, leg. 218, exp. 5142; leg. 219, exp. 5145; 1809. / AGCA, A3, leg. 2585, exp. 38212; 1812. / AGCA, A3, leg. 2585, exp. 38016.
} 
También influyeron en este asunto la Consolidación de Vales Reales promulgada en 1804 y otras necesidades de la monarquía. En ocasiones, debido a que algunas instituciones, como los ayuntamientos, comenzaron a solicitar a renta pupilar los capitales, la disponibilidad para particulares decreció. ${ }^{44}$

Por otro lado, si bien es cierto que los mayores beneficiados de estas dinámicas fueron las personas abonadas, que contaban con los medios suficientes para sufragar los réditos, no fueron las únicas que accedieron a estos capitales. En efecto, se pueden encontrar casos particulares en los que personas de otras capas sociales accedieron a estos fondos. De ahí que sea importante ver a nivel provincial el comportamiento económico de las cajas.

Véase el caso de la india Salomé Quihibix, junto a su hijo Manuel, a quienes en octubre de 1804 se les concedió 1,000 pesos a renta pupilar de las cajas de comunidad de Quetzaltenango. A diferencia de otras personas que pedían el dinero a usura y no especificaban sus motivos, Quihibix precisó que necesitaba el capital para levantar sus cosechas. El acceder a este monto implicaba que Salomé poseía terrenos que se verían beneficiados con los 1,000 pesos. En efecto, los que pretendía habilitar eran compartidos con su fallecido marido, Aniceto López, gobernador indio. La posesión se confirma con la hipoteca de las tierras llamadas "Pacamá", "Limón" y "Salazar". Además de la hipoteca, Quihibix mostró como fiadores a don José Vicente Martínez y a don Juan Antonio López. ${ }^{45}$

Las cajas del reino también dieron préstamos, sin que mediara interés, a otras jurisdicciones para solventar gastos extraordinarios o, bien, saldar las deudas contraídas en pago de maestros u obras públicas. Las cajas de Quetzaltenango se unieron a esta dinámica en ambas vías: como acreedoras y deudoras. Además, aunque los motivos no quedan claros, puede suponerse que los fondos cubrieron gastos en tiempos de crisis. Tampoco puede descartarse que algunos fueran utilizados para dar préstamos con una renta anual fuera de Quetzaltenango. Resaltan préstamos hechos a las alcaldías mayores de Verapaz (1,107 pesos 3/8 reales en 1815), Sacatepéquez ( 1,110 pesos 2 2/8 reales en 1817), Sonsonate (615 pesos $1 \frac{1}{2}$ real en 1819 ), entre otros. ${ }^{46}$

El sostenimiento de la monarquía y las cajas de comunidad

Pese a que los gastos permitidos se solicitaban, precisamente, porque su erogación podía ser cubierta por los sobrantes de las cajas de comunidad, cabe resaltar que era muy poco el marco de acción que este rubro, tras pagar a los maestros de escuela, dejaba para autorizar su uso. Ello se hizo más evidente a finales de la colonia, en tanto la necesidad de la Corona, debido a sus obligaciones fiscales

44 AGCA, A3, leg. 2585, exp. 38212.

45 AGCA, A1, leg. 218, exp. 5142, ff. 1-2; AGCA, A1, leg. 390, exp. 8110. Véase también Grandin, 2000: 34 .

46 AGCA, A1, leg. 2167, exp. 15621. 
y su constante intromisión en nuevos conflictos con otras naciones, pesó más respecto a las necesidades de los pueblos en disponer del capital sobrante. ${ }^{47}$

La ruina económica de la monarquía española ya tenía fuertes ecos al finalizar la década de 1770 , gracias a una serie de guerras en las que se había embarcado la Corona. Para cubrir las necesidades fiscales, momentáneamente, se necesitaron fuertes sumas de dinero que no podían captarse sino de ingresos extraordinarios, principalmente en la forma de donativos forzosos y voluntarios, así como en préstamos que agravaron la deuda pública, lo que desestabilizaría a inicios del siglo xix la economía española (Von Wobeser, 2003: 17-19).

Los bienes de comunidad de los pueblos de indios estuvieron plenamente integrados a estas dinámicas, mediante donativos y empréstitos solicitados desde la década de 1780. En el Reino de Guatemala el caso más conocido es el chiapaneco, pero no deja dudas de que en toda la jurisdicción de la Audiencia la contribución al sostenimiento de la monarquía fue una constante a través del otorgamiento de auxilios fiscales al rey (Guillén, 2018: 153).

A pesar de que existen numerosos casos de este tipo de préstamos y donativos, es preciso referirnos a algunos particulares que permiten mostrar la naturaleza de la relación que sostuvo la Corona con los pueblos de indios a finales del período colonial. El primero es el empréstito patriótico de 1798, con el fin de contribuir con las urgencias de la guerra; el segundo caso corresponde a la aplicación en América de la Consolidación de Vales Reales que tuvo vigencia desde 1805 y se recaudó, al menos, por algunos años más; el tercer caso se refiere a un donativo patriótico y un empréstito hechos en 1809.48

En 1798, una real orden del 20 de mayo enviada por el Ministerio de Hacienda pedía que se remitieran fondos para el remedio de la necesidad regia, que hacía referencia a los estragos que había causado la guerra contra Inglaterra en el erario público. El capitán general, don Joseph Domás y Valle, opinó en el asunto que los bienes de comunidad podían cooperar, por lo que se solicitó un estado de las cantidades con las que se contaba en ese ramo, excluyendo a los propios y arbitrios debido a que sus cargas no se cubrían de forma constante. Tras hacer un conteo de las existencias se decidió que estarían a disposición 69,315 pesos y 5 reales, resultante de las cantidades que se tenían a réditos. ${ }^{49}$ Se hizo de esa forma, aunque, al final, los réditos del empréstito no tuvieron lugar dentro de las cuentas de las cajas de comunidad y el monto suscrito nunca fue redimido, como lo atestigua una Real Cédula de 1802 en la que se explicaba que el monarca no estaba obligado a cubrir la deuda. ${ }^{50}$ Así se continuaba, entonces, con una tradición de presión económica sobre los súbditos americanos.

\footnotetext{
${ }^{47}$ A esta conclusión llega también Tanck (1999: 336) en su estudio de las cajas de comunidad en Nueva España a finales del período colonial.

48 Entre 1801 y 1813, Guillén (2018: 153) refiere cuatro empréstitos forzosos en Chiapas, incluyendo la consolidación de vales reales de 1805 .

49 AGCA, A1, leg. 260, exp. 5729.

50 AGCA, A1, leg. 1536, ff. 291-291v.
} 
Para 1804, durante el reinado de Carlos IV, la deuda pública alcanzó a eclipsar el estado financiero de la monarquía, por lo que se necesitaron medidas más férreas para aplacar la situación. Ya en 1798 se había aplicado una Consolidación de Vales Reales en la península, que consistió en la enajenación de bienes inmuebles y capitales pertenecientes a varias instituciones eclesiásticas, educativas y piadosas, para que ingresaran el valor de la venta de sus bienes en una caja de amortización. Para garantizar la deuda, se establecieron unos réditos del 3\% que los enajenados recibirían por su préstamo (Von Wobeser, 2003: 19-24).

Debido al compromiso económico adquirido por la monarquía española con Napoleón, que consistió en el pago mensual de 6 millones de libras a Francia a cambio del sostenimiento de un acuerdo conocido como Tratado de Suministros, que aseguraba la neutralidad de España con Francia, la Corona pronto se vio en la obligación de extender la Consolidación de Vales Reales a América, lo que fue promulgado en 1804 y aplicado efectivamente al año siguiente. En Guatemala, los efectos de dichas medidas han sido analizados, en buena medida, por Cabat (1971: 28-30), quien explica que después de las capellanías representaron el mayor aporte a la Caja de Consolidación, pese a la discusión entablada en torno a la naturaleza de estos fondos y si el decreto aplicaba a los mismos.

Si bien los bienes de comunidad en los pueblos de indios quedaron inicialmente excluidos del decreto, podían ser sujetos de dar sus sobrantes a la Caja de Consolidación con la recompensa del $5 \%$ que sería pagada en concepto de rédito anual. Este pago se debía hacer de las rentas de la administración general de alcabalas y de la renta de tabaco, lo cual se hizo efectivo desde que se aplicó la medida en el Reino de Guatemala. Dado que una tercera parte estaba destinada al pago de maestros de escuelas de primeras letras, y otros gastos menores, el resto se conocía como sobrante. En tal sentido es que se hizo efectiva la medida, trasladando las dos terceras partes de los fondos a la caja de consolidación. Las intendencias de Ciudad Real y San Salvador figuraron como las que tuvieron mayor contribución a esto - 41,780 pesos y 2 reales y 22,500 pesos, respectivamente-; sin embargo, Quetzaltenango no se quedó atrás, con la cuantiosa contribución de 16,478 pesos y 21/4 reales. En total, el empréstito resultó, únicamente para 1805 , en 139,094 pesos y 5 reales con la contribución de las jurisdicciones del reino. ${ }^{51}$ Además de esto, se remitieron las dos terceras partes de lo que se hubiera redimido en concepto de los préstamos a particulares de las cajas de comunidad para 1805 que, en total, sumó 12,034 pesos 1/2 real (cuadro 1).

51 AGCA, A1, leg. 218, exp. 5142. 


\begin{tabular}{|c|c|c|}
\hline Jurisdicción & Sobrantes ( $2 / 3$ de fondos) & $2 / 3$ de capital redimido \\
\hline Alcaldía mayor de Sololá & 9.484 pesos $31 / 2$ reales & 611 pesos y 5 reales \\
\hline $\begin{array}{l}\text { Intendencia de San } \\
\text { Salvador }\end{array}$ & 22.500 pesos & - \\
\hline Intendencia de Comayagua & 8,374 pesos $1 / 4$ reales & - \\
\hline $\begin{array}{l}\text { Corregimiento de } \\
\text { Chiquimula de la Sierra }\end{array}$ & 11.495 pesos $2 \frac{1}{2}$ reales & 552 pesos $5 \frac{3}{4}$ reales \\
\hline $\begin{array}{l}\text { Corregimiento de } \\
\text { Quetzaltenango }\end{array}$ & 16.478 pesos $2 \frac{1}{4}$ reales & 171 pesos $13 / 4$ reales \\
\hline $\begin{array}{l}\text { Alcaldía mayor de } \\
\text { Totonicapán }\end{array}$ & 16.312 pesos 1 real & - \\
\hline Intendencia de Ciudad Real & 41.780 pesos 2 reales & 2.779 pesos 1 real \\
\hline $\begin{array}{l}\text { Alcaldía mayor de } \\
\text { Sacatepéquez }\end{array}$ & 3.242 pesos $43 / 4$ reales & 1.030 pesos $5 \frac{1}{4}$ reales \\
\hline $\begin{array}{l}\text { Alcaldía mayor de } \\
\text { Sonsonate }\end{array}$ & 4.162 pesos $13 / 4$ reales & - \\
\hline $\begin{array}{l}\text { Alcaldía mayor de } \\
\text { Chimaltenango }\end{array}$ & 5.265 pesos 4 reales & 6.888 pesos $73 / 4$ reales \\
\hline Total & 139.094 pesos 6 reales & 12.034 pesos $2 \frac{1}{2}$ reales \\
\hline
\end{tabular}

Cuadro 1. Remisión de bienes de comunidad a la Caja de Consolidación, 1805 (Fuente: AGCA, A1, leg. 218, exp. 5142).

Como era de esperarse, la mayor contribución en Quetzaltenango provino de la cabecera, Espíritu Santo Quetzaltenango, que entregó 3,714 pesos y 1 1⁄2 reales. Sin embargo, también fueron significativos los aportes de Santa Catarina Zunil, con 2,036 pesos 6 reales, Comitán (actualmente Comitancillo) con 1,063 pesos $1 / 2$ real, entre otros, que oscilaron entre 800 y 900 pesos. El menor aporte provino de Coatepeque (13 pesos), San Pablo y Malacatán (42 pesos 7 reales) y Tejutla (75 pesos $4 \frac{1}{2}$ reales). ${ }^{52}$

Durante 1806 y 1807 también se aportó a la Caja de Consolidación por parte de estos fondos. Así, en diciembre de 1806 se remitieron 61,464 pesos y 4 reales que paraban en la caja de censos, en donde estaban los sobrantes de las cajas de los pueblos. De este total, Quetzaltenango aportó 7,506 pesos y 5 reales. Una contribución menor tuvo lugar en junio de 1807 , cuando se trasladaron 7,372 pesos $1 \frac{1}{4}$ reales proveniente de los ingresos de varios particulares que adeudaban a las cajas de comunidad y otras cantidades que no habían sido trasladadas en los años anteriores, de los cuales 256 pesos $6 \frac{1}{2}$ reales eran de Quetzaltenango. En septiembre de ese año se remitió el monto de 34,705 pesos $23 / 4$ reales que

\footnotetext{
52 AGCA, A1, leg. 218, exp. 5142, f. 76.
} 
paraban en la caja de censos que pertenecían a los mismos bienes, aunque no se especificó qué cantidades pertenecían a los diferentes partidos de la Audiencia. ${ }^{53}$ También hubo aportes en 1808 y 1809, pero no se han podido identificar las cantidades con las que se contribuyó.

En 1809 fueron remitidas dos sumas cuantiosas a la península para ayudar con las urgencias de la monarquía. No obstante, las modalidades fueron distintas en cada una de ellas. Así, en agosto de 1809, después de recibir una orden de la Real Audiencia en la que se solicitaba un estado de los caudales de comunidad para poder remitir un empréstito patriótico a España, el encargado de la mesa de propios, arbitrios y comunidades explicó que no existían cantidades suficientes para suscribir cuantiosos capitales, pues unos días antes se había extraído de la caja de censos un donativo de 100,000 pesos "que los naturales del reino hicieron a su majestad para socorro de la península”. ${ }^{54}$ En esa ocasión, el oficial explicó que el ingreso líquido anual ascendía a 55,935 pesos y 2 reales, del cual se consideraba sujeto a rebaja la tercera parte para pagos de maestros y otros gastos y socorros propios de las comunidades. De esa cuenta, quedaban líquidos 37,290 pesos y $13 / 8$ reales dispuestos a la imposición.

Adicional a ello, eran 19,406 pesos 3/4 reales que ingresaban a la caja de censos proveniente de los réditos del capital impuesto en la caja de consolidación. El principal de las cajas de comunidad era de 388,086 pesos $5 \frac{3}{4}$ reales, que estaban impuestos a usura por la consolidación desde 1805 . Adicionalmente, se contaban los ingresos por concepto de réditos de capitales impuestos a usura pupilar que sumaban 129,447 pesos y 2 3/4 reales, de los cuales se descontaban ciertas cantidades de las que se tenía certeza que no se redimirían o bien que sería poco probable. Por ende, únicamente se podía contar con 95,764 pesos y $2 \frac{3}{4}$ reales. $^{55}$ Al final, fue esto lo que se remitió al provocar que se adelantara la percepción de réditos por parte de individuos y algunas instituciones. ${ }^{56}$

\section{Las cuentas de las cajas de comunidad $^{57}$}

A lo largo de las décadas aquí analizadas los existentes en las cajas de comunidad variaron considerablemente. Esto, desde luego, estuvo relacionado con las urgencias que se tenían dentro de la comunidad e incluso con más influencia las necesidades de la Corona, como ya se ha visto. Tales oscilaciones coincidieron con los

53 AGCA, A1, leg. 2167, exp. 15621, ff. 30-31v.

54 AGCA, A1, leg. 221, exp. 5197, f. 4v.

55 AGCA, A1, leg. 221, exp. 5197.

56 AGCA, A1, leg. 221, exp. 5201.

57 Los datos para elaborar este apartado han sido tomados de AGCA, A1, leg. 2166, exp. 15593, exp. 15594, exp. 15597, exp. 15598, exp. 15607, exp. 15609, exp. 15613; AGCA, A1, leg. 2167, exp. 15620, exp. 15621; AGCA, A1, leg. 2168, exp. 15649, exp. 15623; AGCA, A1, leg. 2522, exp. 36741; AGCA, A3, leg. 5771, exp. 56750 . 
años de crisis monárquica, que tuvo serias implicaciones políticas, económicas y sociales en América. Lejos de afectar únicamente a los centros políticos y económicos, la influencia de estas dinámicas alcanzó a todas las jurisdicciones. En el caso de Quetzaltenango, este contexto se reflejó directamente en las cuentas presentadas por los corregidores y oficiales reales de forma periódica.

La presentación de estados anuales dependía de los corregidores, quienes recibían de manos de las justicias locales los cargos y datas correspondientes al año anterior. En estos últimos se consignaban el resultado de la recolección de la contribución de comunidad, los pagos que se hacían a los maestros y los derechos del escribano que redactaba el estado en cada pueblo - que usualmente se correspondía a uno solo para las 25 cuentas-, entre otros gastos que se presentaban de forma extraordinaria. Con estos datos, el corregidor formaba los estados que eran conocidos en la mesa de propios, arbitrios y bienes de comunidades. Acto seguido, el oficial encargado del ramo los corregía y se elaboraba un nuevo estado.

Desde que se propuso el arreglo de los propios, arbitrios y bienes de comunidades, basándose en la creación de esa mesa a finales del siglo xvII, los estados aparecieron con más frecuencia. Se han encontrado con más abundancia los relativos a las décadas de 1790 y 1800 . Para los últimos diez años antes de la Independencia son más escasos. No obstante, esta situación ha sido remediada parcialmente dado que desde 1809 , conforme a un auto acordado de la Audiencia, los oficiales reales contaban con un libro manual de cargos y datas para cada provincia del reino. En este registro no se consignaban los ingresos anuales en concepto de comunidad, pero sí las existencias catalogadas como "sobrantes" que se encontraban en la caja de censos, lo cual puede dar una idea del líquido con el que los pueblos debían contar más allá del sueldo anual de los maestros, que no se consignaba en los registros dado que no se remitían estas cantidades a la administración fiscal central del reino. ${ }^{58}$

Sobre las cifras que se presentan a continuación vale la pena hacer algunas aclaraciones preliminares. En primer lugar, explicar que los estados anuales corresponden a una forma tradicional de expresar las cuentas en el Antiguo Régimen, a partir de "cargos y datas". La primera categoría — cargo- se refería a la cantidad de la que el oficial se hacía responsable, es decir, con lo que se encontraba anualmente en la caja, sin que esto significara el total de los ingresos en un tiempo determinado. De hecho, hasta 1805 , los cargos crecieron debido a los sobrantes de las cajas. En otro sentido, las datas eran entendidas también como el líquido que dejaba de ser responsabilidad del ministro. Esta explicación es funcional dado que, para presentar las siguientes gráficas, se han hecho modificaciones, explicadas a continuación, a las cuantías que se presentaron

58 Para Quetzaltenango véase AGCA, A1, leg. 2167, exp. 15621. También se ha encontrado el de Totonicapán: AGCA, A1, leg. 2164, exp. 15566. 
anualmente. ${ }^{59}$ También es importante señalar que las cantidades se encuentran expresadas en pesos, aunque las cuentas de las justicias locales se presentaban en tostones.

Las cantidades más constantes en los estados anuales fueron usualmente los ingresos, pues por lo general esta cifra dependía únicamente de lo que aportaba cada pueblo en concepto de cuota de comunidad, las rentas percibidas por la cabecera y otros ingresos extraordinarios que, con el tiempo, se hicieron constantes, tales como la aportación de los ladinos a las cajas de comunidad. La contribución de los pueblos de indios se dejaba de pagar rara vez y, en casos en los que no se enteraba el valor, se hacía en el año o años posteriores. Sin embargo, como lo indican las cifras declaradas por los ministros españoles, las fluctuaciones se caracterizaron por ser constantes desde los primeros años del siglo xIx y, hacia la segunda década, aumentaron, precisamente por lo que inició a percibirse de las cuotas de ladinos.

Si bien los cargos han resultado fundamentales para presentar las cifras, se ha eliminado de esta cantidad los sobrantes anuales para presentar los ingresos. De ella se hacía responsable el corregidor y, por tanto, puede notarse cómo, a partir del arreglo de esos bienes en la década de 1790, las cantidades fluctuaron entre los 3,000 y 4,000 pesos, salvo algunos casos (Gráfica 1).

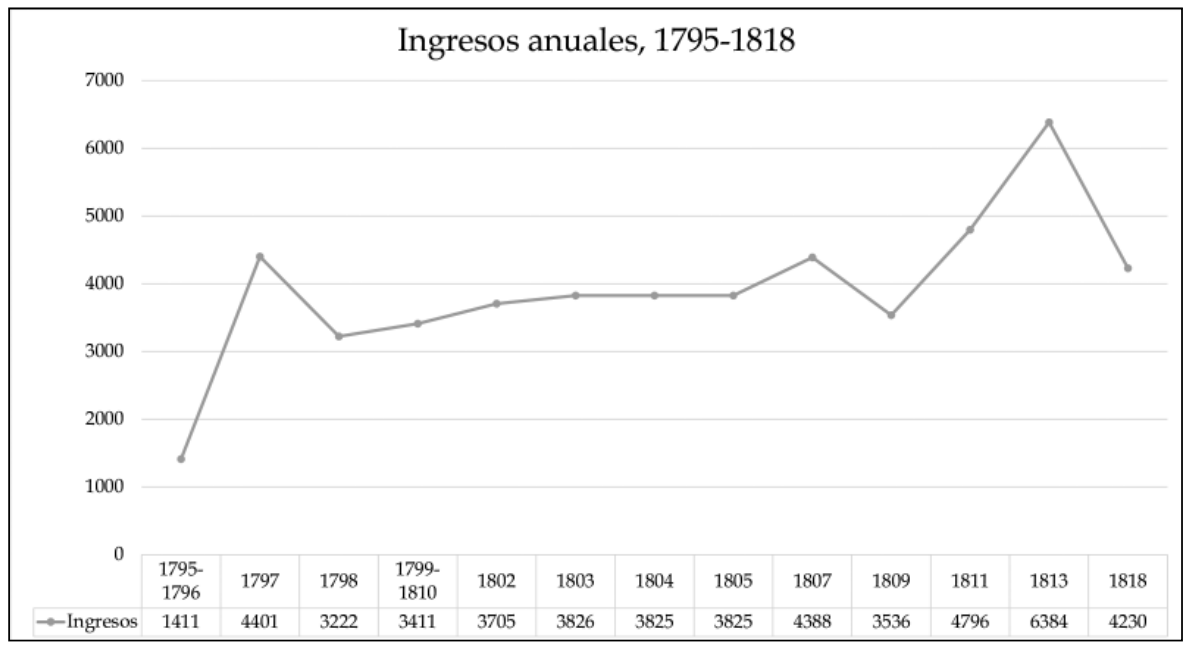

Gráfica 1. Ingresos de las cajas de comunidad en Quetzaltenango en pesos, 1795-1818 (para los años de 1795-1796 se ha hecho un promedio del resultante; lo mismo aplica para los tres años comprendidos entre 1799 y 1801).

\footnotetext{
${ }^{59}$ Sobre las cuentas de los oficiales reales y el manejo de la información a partir de los libros de registro, véase TePaske y Klein, 1986.
} 
Para el caso de los egresos también se han tomado en cuenta algunas consideraciones. Éstas fueron hechas, especialmente, para los datos que se presentaron en los estados anuales después de 1807, en los que se remitieron los sobrantes a la caja de censos, en donde fueron administrados con más soltura por los oficiales reales y, de esa forma, se facilitó el envío de empréstitos y donativos patrióticos, especialmente en el contexto de la guerra contra Napoleón. De esta manera, comprendiendo que el hecho de que el corregidor consignara dichas cantidades como datas no implicó que fuera un egreso como tal, se eliminó del cálculo, ya que únicamente se trató de un traslado de fondos.

El comportamiento de las cajas de comunidad, en términos de egresos, no siempre dependió de los gastos de las comunidades. Por eso, pueden verse las pequeñas cantidades que se desembolsaron, con relación a años posteriores, en la década de 1790, pues no fue sino hasta 1799 que los gastos de escuelas de primeras letras aparecieron. Estas erogaciones permanecieron más o menos constantes a partir de 1802, con variantes que tuvieron que ver con composturas de obras públicas o la asistencia a los pueblos en épocas de epidemias, lo cual no siempre significó que egresara una cantidad significativa respecto a los sobrantes que se acumularon desde 1793 (Gráfica 2).

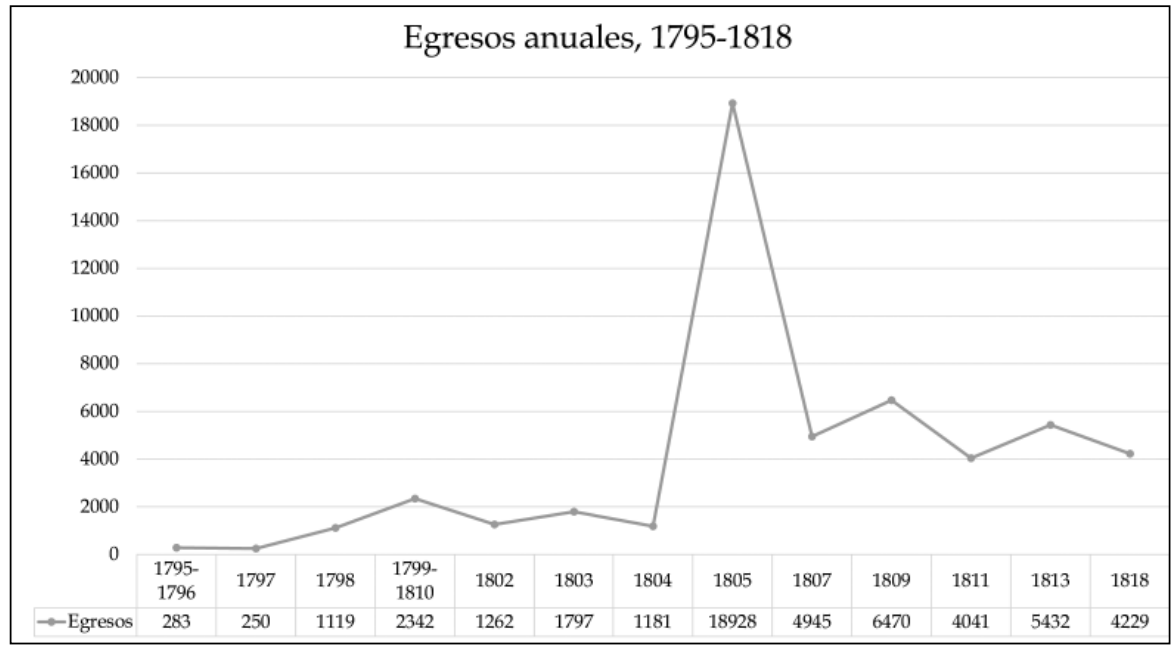

Gráfica 2. Egresos de las cajas de comunidad en Quetzaltenango en pesos, 1795-1818.

El mayor cambio correspondió al año 1805, en el que hubo un desembolso sin precedentes de casi 19,000 pesos, debido a que se destinó buena parte de los fondos, como se explicó en el apartado anterior, para la caja de consolidación. También resalta que hubo gastos que podrían considerarse como "extraordinarios", tales como los presentados para 1809, año en que se gastó en reparos a la iglesia de la cabecera, un retrato donado a la Audiencia, auxilio a unos reos 
en Tapachula, impresión de unas gacetas, entre otros. También se destinaron fondos para habilitación de indígenas, debido al difícil momento económico que atravesaba Quetzaltenango y, en general, todo el reino, debido a una serie de desastres naturales y una prolongada crisis agraria y comercial. Debido a ello, no fueron pocas las veces en que los fondos de comunidades buscaron aliviar la situación destinándolos para fomentar la agricultura (cfr. González, 2017: 177-192).

Finalmente, respecto a los sobrantes es importante señalar que las decisiones metodológicas para tratar los datos proporcionados por los estados de los corregidores y el libro manual de los oficiales reales desde 1809 no han sido menores. De los años que se tiene constancia en ambas fuentes (estados y libro manual) se pudo constatar que se consideraban sobrantes las cantidades dirigidas al pago de maestros que, sin embargo, en el año siguiente se gastaban casi en su totalidad. Esto correspondía a una tercera parte del total de existencias al finalizar los doce meses. Las dos terceras partes restantes eran las que estaban disponibles para ser trasladas a la caja de censos, en donde los oficiales reales disponían de ellas. Por tanto, únicamente se ha considerado como sobrante esta última cifra.

En los años estudiados, el sobrante de las comunidades fue en ascenso ininterrumpidamente hasta 1805 , año en que se puso en vigencia la consolidación de vales reales. A partir de ahí, hubo un descenso dramático. Estos datos también indican que, aunque los réditos eran pagados por la administración general de alcabalas y la renta de tabacos - de lo cual existe constancia-, el total nunca fue remitido a las cajas de comunidad o, bien, a la caja de censos. De esa cuenta, la recuperación de este rubro, al finalizar el período colonial, únicamente se pudo asistir, de manera notable, tras 1814 (Gráfica 3). De ello se puede concluir que, hacia finales de la colonia, las cajas de comunidad no pertenecían a los indios tributarios más allá de la relación virtual que sostenían con el monarca.

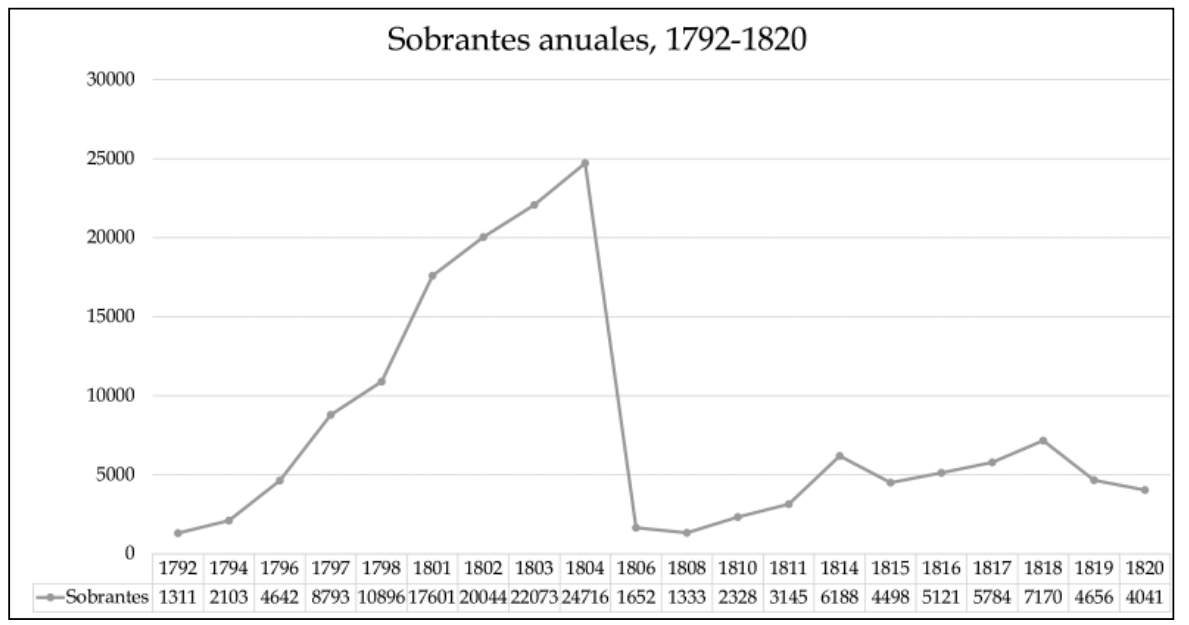

Gráfica 3. Sobrantes de las cajas de comunidad en Quetzaltenango en pesos, 1792-1820. 


\section{Reflexiones finales}

Durante todo el período colonial, las instituciones de origen castellano influyeron fuertemente en la vida política, social y económica de la población indígena. De esta forma, el pueblo de indios fue fundamental en tal dinámica. Paralelo a ello, la introducción de las cajas de comunidad tuvo gran relevancia en tanto sufragó una conjunto de gastos. Además, aunque estas cajas respondieron al contexto de cada jurisdicción, es importante señalar que estuvieron sujetas a los ecos de los cambios a escala monárquica y, desde luego, a la administración provincial, lo que explica la importancia que tuvo esta institución, especialmente para el período estudiado en las líneas precedentes.

En efecto, comenzando por el análisis breve del marco normativo, se ha podido constatar lo que varios autores han establecido para Nueva España y Guatemala al final del período colonial: el control riguroso al que fueron sometidos estos fondos bajo el manto del reformismo borbónico y a merced de la crisis monárquica. Sin duda, la revisión de más disposiciones normativas sobre las cajas de comunidad contribuirá a una mejor comprensión de la institución y, por otro lado, ayudará a conocer cómo, en contexto provincial y local, esta normativa era aplicada y negociada en los casos en que era posible.

Dado que el trabajo que se presenta pretendía comprender las dinámicas para una jurisdicción particular, enfocándose en la administración de los fondos y su gasto, el caso de Quetzaltenango fue apropiado en tal sentido. Como advertimos arriba, el estudio a nivel provincial es fundamental porque da una visión de conjunto de una jurisdicción con un puñado de pueblos que, si bien numerosos, representan un abanico de casos manejables para un estudio de los alcances aquí mostrados. De ahí que se haya enfatizado en mostrar las diferencias notables entre las cajas de pueblos como la cabecera y otros, con una cantidad pequeña de tributarios, como Coatepeque, Tejutla o Sipacapa, por ejemplo.

Los bienes de comunidad fueron importantes para la instalación de escuelas de primeras letras. Éstas fueron puestas en funcionamiento en Quetzaltenango en los últimos años del siglo xvIII y, como se despliega de las cuentas presentadas, fueron fuente de inversión considerable proveniente, exclusivamente, de los bienes de comunidad. Puede notarse cómo, a finales del período colonial, la instrucción de los indios fue una prioridad que no sólo quedó en el discurso ilustrado, sino que se materializó en el ramo educativo. Adicional a ello, los gastos en casos de epidemias o, bien, aquellas erogaciones devenidas de la prevención de las mismas, fueron rubros importantes que se buscaron sufragar con tales fondos. En este sentido, resalta la importancia de las cajas en mantener una relativa estabilidad demográfica entre la población indígena. En resumen, entre escuelas de primeras letras, epidemias y otros gastos, como la reparación de obras públicas, los fondos de comunidad ciertamente seguían siendo vitales dentro del pueblo de indios, aunque su naturaleza varió considerablemente a finales del período colonial. 
Además de los gastos al interior del corregimiento, el uso de estos fondos con fines crediticios fue también relevante, en tanto contribuyó a la financiación de la economía española de manera considerable. Este aspecto debe seguir profundizándose, especialmente en tanto pueda compararse, en futuros estudios, con los capitales eclesiásticos y comerciales. Aun así, no se puede dudar de la importancia que tuvieron las cajas de comunidad para el sostenimiento económico del reino, una vez que buena parte de los capitales destinados al financiamiento se encontraban agotados por la crisis de inicios de siglo. A ello debe sumarse la capacidad que las cajas de comunidad tuvieron para prestar a otras provincias en momentos de necesidad.

Más allá de este aspecto, no puede dejar de considerarse a los bienes de comunidad como una fuente económica importante en el sostenimiento de la monarquía. En primer lugar, con los donativos y empréstitos patrióticos que, a menudo, se hicieron de manera forzosa. En segunda instancia, vale la pena analizar a profundidad los efectos de la consolidación de vales reales en estos caudales. Fue así cómo, a partir de las necesidades fiscales de la Corona, los bienes de comunidad se vieron fuertemente afectados y, pese al lento crecimiento presentado en los últimos años anteriores a la Independencia, nunca alcanzaron el nivel económico mantenido hacia 1805 . De ahí que desde hace varias décadas la historiografía especializada no ha dudado en afirmar que estas cantidades estaban mayormente a disposición de intereses externos a la comunidad indígena. La revisión de las cuentas para la mayor cantidad de jurisdicciones posible, al interior de la jurisdicción de la Audiencia de Guatemala, dará más luces al respecto y permitirá, sin duda, hacer un estudio con mayores alcances.

\section{Bibliografía}

Belaubre, Christophe

2012 Élus de dieu et élus du monde dans le Royaume du Guatemala (1753-1808). Paris: L'Harmattan.

Cabat, Geoffrey A.

1971 "The Consolidation of 1804 in Guatemala", The Americas, 28 (1): 20-38. Dol: https://doi.org/10.2307/980342.

Cox-Collins, Anne

1980 "Colonial Jacaltenango, Guatemala: The Formation of a Corporate Community", tesis de doctorado en Historia. New Orleans: Tulane University, Department of History.

Dym, Jordana

2006 From Sovereign Villages to National States: City, State, and Federation in Central America, 1759-1839. Albuquerque: University of New Mexico Press. 
Few, Martha

2015 For All of Humanity. Mesoamerican and Colonial Medicine in Enlightenment Guatemala. Tucson: University of Arizona Press.

Fry, Michael

1988 “Agrarian Society in the Guatemalan Montaña, 1700-1840”, tesis de doctorado en Historia. New Orleans: Tulane University, Department of History.

García Martínez, Bernardo

2005 Los pueblos de la sierra: el poder y el espacio entre los indios del norte de Puebla hasta 1700. México: El Colegio de México.

González Alzate, Jorge

2017 La experiencia colonial y transición a la independencia en el occidente de Guatemala. Quetzaltenango: de pueblo indígena a ciudad multiétnica, 1520-1825. Mérida: Universidad Nacional Autónoma de México, Centro Peninsular en Humanidades y Ciencias Sociales.

Grandin, Greg

2000 The Blood of Guatemala. A History of Race and Nation. Durham: Duke University Press.

Guillén Villafuerte, José Javier

2018 "Guerras imperiales, donativos patrióticos y pueblos de indios en Chiapas, 1780-1814”, Fronteras de la Historia, XXIII (1): 128-161. Dol: https://doi. org/10.22380/20274688.314.

Herrera, Sajid Alfredo

2007 "Primary Education in Bourbon San Salvador and Sonsonate, 1750-1808", Politics, Economy, and Society in Bourbon Central America, 1759-1821, pp. 1745, Jordana Dym y Christophe Belaubre (eds.). Boulder: University Press of Colorado.

León Maldonado, Oralia de

2002 Los fondos de bienes de comunidades indígenas en el Reino de Guatemala (1550-1821). Guatemala: Universidad de San Carlos, Dirección General de Investigación.

Lira González, Andrés

1984 "La voz comunidad en la Recopilación de 1680", Relaciones. Estudios de Historia y Sociedad, V (18): 74-92.

López Mejía Velásquez, María Eugenia

2017 "Pueblos de indios, de ladinos y de mulatos de San Salvador y Sonsonate en tiempos de reformas y transiciones políticas (1737-1841)", tesis de doctorado en Ciencias Sociales. Zamora: El Colegio de Michoacán.

Lovell, W. George

2015 Conquista y cambio cultural: la sierra de los Cuchumatanes de Guatemala, 1500- 
1821. La Antigua Guatemala: Centro de Investigaciones Regionales de Mesoamérica, Asociación para el Desarrollo de las Finanzas Rurales, Plumsock Mesoamerican Studies.

Lovell, George, Christopher Lutz, Wendy Kramer y William Swezey

2013 Strange Lands and Different Peoples: Spaniards and Indians in Colonial Guatemala. Norman: University of Oklahoma Press.

McCreery, David

1992 "Caja, Cofradía, and Cabildo: The Transformation of 'Broker' Institutions in Nineteenth Century Guatemala", trabajo presentado en Conference on Ethnicity and Power in Mexico and Guatemala. Austin: University of Texas at Austin.

1994 Rural Guatemala, 1760-1940. Stanford: Stanford University Press.

Menegus Bornemann, Margarita

2001 "Los bienes de comunidad de los pueblos de indios a fines del período colonial”, Estructuras y formas agrarias en México, del pasado y del presente, pp. 84-118, Antonio Escobar y Teresa Rojas (coords.). México: Registro Agrario Nacional, Archivo General Agrario, Centro de Investigaciones y Estudios Superiores en Antropología Social.

Obara-Saeki, Tadashi y Juan Pedro Viqueira Albán

2017 El arte de contar tributarios: provincia de Chiapas, 1560-1821. México: El Colegio de México, Centro de Estudios Históricos.

Owensby, Brian

2008 Empire of Law and Indian Justice in Colonial Mexico. Stanford: Stanford University Press.

Pietschmann, Horst

1996 Las reformas borbónicas y el Sistema de Intendencias en Nueva España. Un estudio político administrativo. México: Fondo de Cultura Económica.

Real ordenanza para el establecimiento e instrucción de intendentes de exército y provincia en el Reino de la Nueva España

1786 Madrid: Viuda de Joaquín Ibarra, Hijos y Compañía.

Recopilación de leyes de los reynos de las Indias

1681 Madrid: Iulian de Paredes.

Sagastume Paiz, Tania

2015 "Introducción al estudio de la legislación sobre bienes y tierras de pueblos indígenas en Guatemala, 1750-1812”, Anuario Estudios, tercera época: 43-81.

Solórzano Fonseca, Juan Carlos

1985 "Las comunidades indígenas de Guatemala, El Salvador y Chiapas durante el siglo xvIII: los mecanismos de la explotación económica”, Anuario de Estudios Centroamericanos, 11 (2): 93-130. 
Solórzano Vega, Abraham Israel

2014 "Los métodos físicos y médicos de prevención y erradicación de las epidemias de viruela utilizados por el gobierno del Reino de Guatemala de 1780 a 1820", Tradiciones de Guatemala, LXXXI: 229-291.

Tanck de Estrada, Dorothy

1994 "Escuelas y cajas de comunidad en Yucatán al final de la Colonia", Historia Mexicana, XLIII (3): 401-449.

1999 Pueblos de indios y educación en el México colonial, 1750-1821. México: El Colegio de México.

TePaske, John y Herbert Klein

1986 Ingresos y egresos de la Real Hacienda de Nueva España. México: Instituto Nacional de Antropología e Historia.

Terán, Marta

1999 "La relación de las cajas de comunidad de los pueblos indígenas michoacanos con la Real Hacienda entre 1779 y 1810", Estudios Michoacanos VIII, pp. 221-253, Bárbara Skinfill y Alberto Carrillo (eds.). Zamora: El Colegio de Michoacán.

Von Wobeser, Gisela

2003 Dominación colonial. La consolidación de Vales Reales en Nueva España, 18041812. México: Universidad Nacional Autónoma de México, Instituto de Investigaciones Históricas.

Wortman, Miles

2012 Gobierno y sociedad en Centroamérica, 1680-1840. Guatemala: Universidad Rafael Landívar, Editorial Cara Parens.

Zilbermann de Luján, Cristina

1995 "El régimen de Intendencias", Historia General de Guatemala. Siglo XVIII hasta la Independencia, tomo III, pp. 33-38, Jorge Luján Muñoz y Cristina Zilbermann de Luján (dirs.). Guatemala: Asociación de Amigos del País, Fundación para la Cultura y el Desarrollo.

\section{Documentos de archivo}

Archivo General de Centroamérica (AGCA).

A1, leg. 12, exp. 285, "Real Orden en que se derogan los artículos 6 y 28 de la Real Ordenanza de Intendentes". Guatemala, 1788.

A1, leg. 218, exp. 5142, "Remisión de bienes de comunidad a la Caja de Consolidación en 1805". Guatemala, 1805.

A1, leg. 219, exp. 5145, "Sobre traslado a la Real Caja de Consolidación de 2/3 partes de las cantidades impuestas a usura y redimidas de los fondos de comunidad". Guatemala, 1805.

A1, leg. 221, exp. 5197, "El oficial de la mesa de propios, arbitrios y comunidades sobre 
un empréstito patriótico a España de los fondos de comunidad de todo el Reino de Guatemala”. Guatemala, 1809.

A1, leg. 221, exp. 5201, "Informe sobre escasez de fondos de comunidad por darlos a usura”. Guatemala, 1809.

A1, leg. 260, exp. 5729, "Cumplimiento de lo ordenado por Su Majestad sobre que se remita lo existente para gastos de guerra”. Guatemala, 1798.

A1, leg. 260, exp. 5736, "Sobre la instrucción en las escuelas de primeras letras en pueblos de indios". Guatemala, 1799.

A1, leg. 272, exp. 5865, "Instancia del fiscal acerca de la creación de la Contaduría de Propios, arbitrios y bienes de comunidad”. Guatemala, 1791.

A1, leg. 389, exp. 8101, "El corregidor de Quetzaltenango solicita gastar 84 pesos de los fondos de comunidad para reparar la casa real de la cabecera”. Quetzaltenango, 1796.

A1, leg. 390, exp. 8110, "Sobre el dinero dado a la india Salomé Quihibix de las cajas de Quetzaltenango". Guatemala, 1804.

A1, leg. 1536, f. 291, "Real Cédula sobre el empréstito de 1798 y la obligación de cubrir los réditos". Madrid, 1802.

A1, leg. 2164, exp. 15566, "Libro manual de cargos y datas de los fondos de comunidad de la alcaldía mayor de Totonicapán”. Guatemala, 1808-1824.

A1, leg. 2166, exp. 15593, "Cuenta general de los fondos de comunidad de Quetzaltenango en 1795 y 1796". Quetzaltenango, 1797.

A1, leg. 2166, exp. 15594, "Cuenta general de los fondos de comunidad de Quetzaltenango en 1797". Quetzaltenango, 1798.

A1, leg. 2166, exp. 15597, "Estado de las existencias en las cajas de comunidad de los pueblos de Quetzaltenango en 1793". Quetzaltenango, 1794.

A1, leg. 2166, exp. 15598, "Cuenta general de los fondos de comunidad de Quetzaltenango en 1798 ”. Quetzaltenango, 1799.

A1, leg. 2166, exp. 15607, "Cuenta general de los fondos de comunidad de Quetzaltenango en 1801". Quetzaltenango, 1802.

A1, leg. 2166, exp. 15609, "Cuenta general de los fondos de comunidad de Quetzaltenango en 1802". Quetzaltenango, 1803.

A1, leg. 2166, exp. 15613, “Cuenta general de los fondos de comunidad de Quetzaltenango en 1803". Quetzaltenango, 1804.

A1, leg. 2167, exp. 15620, "Cuenta general de los fondos de comunidad de Quetzaltenango en 1805 ”. Quetzaltenango, 1806.

A1, leg. 2167, exp. 15621, "Libro manual de cargos y datas de los fondos de comunidad del corregimiento de Quetzaltenango". Guatemala, 1808-1824.

A1, leg. 2168, exp. 15623, "Cuenta general de los fondos de comunidad de Quetzaltenango en 1818 ". Quetzaltenango, 1819.

A1, leg. 2168, exp. 15624, "Cuenta general de los fondos de comunidad de Quetzaltenango en 1811". Quetzaltenango, 1812.

A1, leg. 2168, exp. 15641, "Gastos habidos en San Miguel Ixtahuacán por una epidemia de fiebre”. Quetzaltenango, 1813.

A1, leg. 2168, exp. 15642, "Gastos habidos en San Miguel Ixtahuacán por una epidemia de fiebre”. Quetzaltenango, 1813.

A1, leg. 2168, exp. 15643, "Gastos habidos en San Miguel Ixtahuacán por una epidemia de fiebre”. Quetzaltenango, 1813.

A1, leg. 2168, exp. 15644, "Gastos habidos en San Miguel Ixtahuacán por una epidemia de fiebre”. Quetzaltenango, 1813. 
A1, leg. 2168, exp. 15649, "Cuenta general de los fondos de comunidad de Quetzaltenango en 1813”. Quetzaltenango, 1814.

A1, leg. 2168, exp. 15656, "Cuenta general de los fondos de comunidad de Quetzaltenango en 1817". Quetzaltenango, 1818.

A1, leg. 2807, exp. 24704, "El común de Zunil pide que se rebaje su contribución al fondo común a 2 reales en lugar de los 4 que deben enterar”. Quetzaltenango, 1797.

A1, leg. 6099, exp. 55567, "Estado de los fondos de comunidad de todas las provincias del Reino de Guatemala y cantidades con las que pueden contribuir para los objetos de la capital". Guatemala, 1805.

A3, leg. 2522, exp. 36741, "Cuenta general de los fondos de comunidad de Quetzaltenango en 1804". Quetzaltenango, 1805.

A3, leg. 2585, exp. 38016, "Inventario general del Juzgado de censos de comunidades". Guatemala, 1812.

A3, leg. 5771, exp. 56750, "Cuenta general de los fondos de comunidad de Quetzaltenango en 1807 ”. Quetzaltenango, 1808.

Selvin Chiquín. Guatemalteco. Licenciado en Historia por la Universidad de San Carlos de Guatemala. Su especialidad es la historia del Reino de Guatemala (instituciones, sociedad y economía), así como de Guatemala durante el siglo XIX y principios del xx. Entre sus publicaciones más recientes se encuentran "Publicidad ilustrada y secularización. El caso del convento de Santa Teresa en la Ciudad de Guatemala, 1816-1826", "Separación y divorcio en Chiquimula a inicios del siglo xx. Economía moral, amor y honor" y "Vínculos de papel: representación, actores y distancia en el Reino de Guatemala (1800-1820)".

chiquin.selvin@gmail.com 